\title{
EXPERIMENTAL VALIDATION OF OPTIMUM RESISTANCE MOMENT OF CONCRETE SLABS REINFORCED WITH CARBON FIBRE-REINFORCED PLASTIC
}

\author{
E. E. Okoro ${ }^{1,}{ }^{*}$, A. U. Nwafor ${ }^{2}$ and O. S. Abejide ${ }^{3}$ \\ 1Department of Civil Engineering, WaZiri Umaru Federal Polytechnic, Birnin KebBi, KebBi State. NiGERIA. \\ ²Department of Civil EngineEring, Federal Polytechnic, OKo, Anambra State. NigERIA. \\ 3DEPARTMEnT OF Civil Engineering, Ahmadu Bello University, Zaria, Kaduna State. NIGERIA. \\ E-mail addresses:1emmadinma90@yahoo.com2 listentony@yahoo.co.uk,3abejideos@yahoo.com
}

\begin{abstract}
Fibre-Reinforced Plastics (FRPs) have been suggested as suitable reinforcement for concrete structures among other solutions to combat corrosion problems in steel reinforced concrete. This paper presents the experimental validation of optimum resistance moment of concrete slabs reinforced with Carbon-Fibre Reinforced Plastic (CFRP). Eight specimens of two-way spanning slabs reinforced with CFRP bars were used in the experiment. They were designed to achieve two classical failure modes: rupture of the reinforcements (tension failure) and crushing of the concrete while the reinforcement remains elastic (compression failure). This was accomplished by using reinforcement ratios less, and more than the balanced reinforcement ratio, $\rho_{\text {frpb }}$, for the slabs, respectively. All the slabs failed as predicted. The results obtained show that the design formulations for predicting the minimum flexural resistance of an CFRP-reinforced concrete member provided by CSAS806-02(R07) have been underestimated. The design formulations were found to underestimate the resistance moment capacity of CFRP-reinforced concrete slabs by about $33 \%$.
\end{abstract}

Keywords: optimum resistance moment, concrete slabs, CFRP, design formulation.

\section{INTRODUCTION}

One of the major concerns about steel as reinforcement for concrete structures is its susceptibility to corrosion in a wet and harsh environment. Aggressive environments are not concrete-friendly because in an aggressive environment concrete may be open to chemical attacks, which break down the alkaline barrier in the cement matrix. This exposes the steel reinforcement in the concrete structures to corrosion, resulting in a loss of strength for the steel and structural capacity of the reinforced member. For this and many other reasons, Fibre-Reinforced Polymer (FRP) bars are considered as an alternative to steel for concrete reinforcement. However, the apparent high cost of FRP in comparison with steel and other conventional materials, has been a disapproving restraint [1]. Aside the cost concerns, the most significant technical obstacle stopping the extended use of FRP materials is lack of long-term and durability performance information comparable to the information available for traditional construction materials [2].Most of the information available on composites is not related to civil engineering applications. Also, the absence of reliable design methods to determine the ultimate strength of structural elements reinforced with FRP has inhibited its use in the construction industry, despite its numerous advantages. Inspite of all these inhibitions, FRP-reinforcement in concrete structures are gaining wide acceptance as an effective substitute for steel reinforcement, especially for the cases in which aggressive environment produces high steel corrosion, or lightweight is an important design factor, or transportation cost increase substantially with the weight of the materials.

Pultrusion, braiding, and filament winding are three common processes of manufacturing FRP [3]. Pultrusion is one of the most popular and common methods for producing linear composite elements with the primary reinforcing fibres in the longitudinal direction. It is a continuous filament moulding process incorporating fibre reinforcement with thermosetting resin matrices [4]. Continuous strands of reinforcing material are drawn from spools of fibres, through a resin tank, where they are saturated with resin, and then through a number of wiper rings into the mouth of a heated die. This process simultaneously forms and heat-cures the FRP into reinforcing rods [3]. The speed of pulling through the die is predetermined by the curing time needed. To ensure 
good and strong bond with concrete, the surface of the bars is usually interwoven, spiral wound or sand-coated. Lightly reinforced sections may fail immediately after cracking if the flexural strength or resistance moment of the reinforced element is less than the cracking moment for the member [5]. This type of failure occurs suddenly and without warning, and must be avoided. For this reason, [6] provides for minimum flexural resistance by requiring the resistance moment of an FRP-reinforced concrete member, $\mathrm{M}_{\mathrm{r}}$, to be at least $50 \%$ greater than the cracking moment, $\mathrm{M}_{\mathrm{cr}}$. However, [7] opined that this value could be stepped up to about $33 \%$ to get the optimum resistance moment. They stated that the resistance moment capacity of FRP-reinforced concrete slabs has been underestimated by about $33 \%$ in the design formulations by the code. This paper presents the experimental validation of the optimum resistance moment of concrete slabs reinforced with Carbon FibreReinforced Plastic (CFRP) proposed by [7].

\section{MINIMUM FLEXURAL RESISTANCE OF FRP- REINFORCED RECTANGULAR CONCRETE SECTIONS}

The moment of resistance of a beam or slab section is the moment of the couple which is set up at the section by the longitudinal forces created in the beam or slab by its deflection. The minimum resistance moment of FRPreinforced concrete sections is given by [6] as:

$$
M_{r} \geq 1.5 M_{c r}
$$

The cracking moment $\left(\mathrm{M}_{\mathrm{cr}}\right)$ is determined from the modulus of rupture of the concrete, $f_{r}$ the moment of inertia of the transformed uncracked section, $\mathrm{I}_{\mathrm{r}} \mathrm{a}$ and the distance from the centroidal axis of the transformed uncracked section to the extreme tension fibre, $y_{r}$, using [5]:

$$
M_{c r}=\frac{f_{r} I_{r}}{y_{t}}
$$

In (2), $f_{r}=0.6 \sqrt{f_{c}}$ is the modulus of rupture of concrete, $M_{c r}$ is the cracking moment, $I_{t}$ is the Moment of inertia of transformed uncracked section and $y_{t}$ is the Distance from the centroidal axis of transformed uncracked section to the extreme tension fibre.

However, [6] and [8] permit the use of the gross moment of inertia, $I_{g}$ instead of $I_{t}$ to compute $M_{c r}$

The general ultimate moment for a singly FRP reinforced concrete section is given by [6] as Equation (1) above, which is equivalent to:

$$
M_{r}=0.25 f_{r} b d^{2}
$$

This equation is proposed by [5] to be represented as:

$$
M_{r}=0.25 \beta_{0} f_{r} b d^{2}=k b d^{2}
$$

where, $\beta_{0}$ is an underestimation factor observed in the cracking moment of concrete, and

Therefore, $\beta_{0}=\frac{k}{0.25 f_{r}}$

$$
k=0.25 \beta_{0} f_{r}
$$

From [5], $\mathrm{k}$ is given as:

$$
k=\frac{1}{\left(C_{o p t}^{m}\right)^{2}}
$$

where:

$$
C_{o p t}^{m}=\frac{\left(1.8656 f_{f r p}-f_{c}\right)}{\sqrt{\left[f_{f r p} f_{c}\right]\left(0.6996 f_{f r p}-0.75 f_{c}\right)}}
$$

$C_{o p t}^{m}$ is the maximum optimum design variable, $\mathrm{k}$ is a function of $C_{o p t}^{m}$ and $K_{o p t}^{m}$ is the maximum optimum value of k. Equation (7) implies that the value of $C_{o p t}^{m}$ can be determined at every choice of concrete and CFRP strength in a reinforced concrete slab section. For instance, if $f_{c}=25 \mathrm{~N} / \mathrm{mm}^{2}$ and $f_{\text {frp }}=1431 \mathrm{~N} /$ $m m^{2} C_{o p t}^{m}=0.44075$. and $K_{o p t}^{m}=5.00354$. Consequently, (5) becomes:

$$
0.25 \beta_{0} f_{r}=5.00354
$$

Therefore, $\beta_{0}=6.67139$. It was observed that this same value is not obtained for other CFRP-singly reinforced sections with various combinations of CFRP and concrete strengths. The value of modulus of rupture, $f_{r}$ of concrete seems very conservative compared to steel reinforced concrete. For a higher value of modulus of rupture of concrete, $f_{r}$ which is $0.8 \sqrt{f_{c}}, \quad \beta_{0}$ becomes 5.00354 .

Taking ratio of $\beta_{0}$ for $0.6 \sqrt{f_{c}}$ to $\beta_{0}$ for $0.8 \sqrt{f_{c}}$, gives a value of 1.3333333333 for various combinations of CFRP and concrete strengths [9]. This is shown in Table 1.

\section{MATERIALS AND METHODS}

\subsection{Materials}

Two sizes of CFRP reinforcement bars, $8 \mathrm{~mm}$ and $3 \mathrm{~mm}$ diameters, produced by Mitsubishi Chemical Company, Japan, were used in the test programme. The diameters of the bars were measured as $7.98 \mathrm{~mm}$ and $2.87 \mathrm{~mm}$ for the 8 and $3 \mathrm{~mm}$ diameters respectively. The measured diameters and the manufacturers' guaranteed tensile strengths of $1970 \mathrm{~N} / \mathrm{mm}^{2}$ and $1431 \mathrm{~N} / \mathrm{mm}^{2}$ for $8 \mathrm{~mm}$ and $3 \mathrm{~mm}$ bars respectively, were used in the design calculations. Normal concrete of $25 \mathrm{~N} / \mathrm{mm}^{2}$ compressive strength was used. This was ascertained by laboratory tests.

\subsection{Specimens}

Eight specimens of two-way spanning slabs reinforced with CFRP bars were used in the experiment. They were designed to achieve two classical failure modes: rupture of the reinforcements (tension failure) and crushing of the concrete while the reinforcement remains elastic (compression failure). This was accomplished by using reinforcement ratios less, and more than the balanced reinforcement ratio, $\rho_{f r p b}$, for the slabs, respectively. Table 2 gives the details of test specimens. 
Table 1: Underestimation for various CFRP-singly reinforced concrete sections

\begin{tabular}{|c|c|c|c|c|c|c|c|c|c|}
\hline $\mathrm{S} / \mathrm{N}$ & $\begin{array}{c}\text { Strength } \\
\text { of } \\
\text { CFRP } \\
\mathrm{N} / \mathrm{mm}^{2}\end{array}$ & $\begin{array}{c}\text { Strength } \\
\text { of } \\
\text { Conc } \\
\mathrm{N} / \mathrm{mm}^{2}\end{array}$ & $C_{o p t}^{m}$ & $K_{o p t}^{m}$ & $\begin{array}{c}\beta_{0} \text { for } \\
0.6 \sqrt{f_{c}} \\
\text { (1) }\end{array}$ & $\begin{array}{c}\beta_{0} \text { for } \\
0.8 \sqrt{f_{c}} \\
(2)\end{array}$ & $\begin{array}{l}\text { Ratio } \\
\frac{1}{2}\end{array}$ & $\begin{array}{c}\% \\
\text { Under } \\
\text { estima } \\
\text { tion }\end{array}$ & $\begin{array}{c}\text { Objective } \\
\text { Function } \\
\text { Y }\end{array}$ \\
\hline \multirow{7}{*}{1} & \multirow{7}{*}{1431} & 20 & 0.49981 & 4.00299 & 5.96749 & 4.47548 & 1.333 & 33.33 & 0.5941 \\
\hline & & 25 & 0.44705 & 5.00354 & 6.67139 & 5.00354 & 1.333 & 33.33 & 0.5312 \\
\hline & & 30 & 0.40811 & 6.00396 & 7.30779 & 5.48084 & 1.333 & 33.33 & 0.4849 \\
\hline & & 35 & 0.37785 & 7.00423 & 7.89288 & 5.91966 & 1.333 & 33.33 & 0.4488 \\
\hline & & 40 & 0.35345 & 8.00434 & 8.43731 & 6.32798 & 1.333 & 33.33 & 0.4198 \\
\hline & & 50 & 0.31014 & 10.3961 & 9.80159 & 7.35119 & 1.333 & 33.33 & 0.3682 \\
\hline & & 60 & 0.28312 & 12.4749 & 10.7367 & 8.05257 & 1.333 & 33.33 & 0.3360 \\
\hline \multirow{7}{*}{2} & \multirow{7}{*}{1970} & 20 & 0.49875 & 4.02008 & 1.49819 & 1.12365 & 1.333 & 33.33 & 0.5920 \\
\hline & & 25 & 0.44610 & 5.02499 & 1.67499 & 1.25625 & 1.333 & 33.33 & 0.5393 \\
\hline & & 30 & 0.40724 & 6.02975 & 1.83479 & 1.37610 & 1.333 & 33.33 & 0.4924 \\
\hline & & 35 & 0.37703 & 7.03474 & 1.98181 & 1.48636 & 1.333 & 33.33 & 0.4861 \\
\hline & & 40 & 0.35269 & 8.03922 & 2.11852 & 1.58889 & 1.333 & 33.33 & 0.4261 \\
\hline & & 50 & 0.31546 & 10.0487 & 2.36850 & 1.77638 & 1.333 & 33.33 & 0.3787 \\
\hline & & 60 & 0.28799 & 12.0572 & 2.59430 & 1.94572 & 1.333 & 33.33 & 0.3478 \\
\hline \multirow{7}{*}{6} & \multirow{7}{*}{2255} & 20 & 0.49857 & 4.02006 & 5.99275 & 4.49456 & 1.333 & 33.33 & 0.59401 \\
\hline & & 25 & 0.44609 & 5.02501 & 6.70001 & 5.02501 & 1.333 & 33.33 & 0.53130 \\
\hline & & 30 & 0.40723 & 6.02992 & 7.33938 & 5.50539 & 1.333 & 33.33 & 0.48202 \\
\hline & & 35 & 0.37702 & 7.03477 & 7.92729 & 5.94547 & 1.333 & 33.33 & 0.44849 \\
\hline & & 40 & 0.35268 & 8.03956 & 8.47444 & 6.35583 & 1.333 & 33.33 & 0.41953 \\
\hline & & 50 & 0.31545 & 10.0489 & 9.47422 & 7.10566 & 1.333 & 33.33 & 0.37505 \\
\hline & & 60 & 0.28798 & 12.0579 & 10.3778 & 7.78336 & 1.333 & 33.33 & 0.33190 \\
\hline
\end{tabular}

\subsection{Experimental Procedure}

Figure 1 shows a schematic diagram of the test setup. The slab is a two-way spanning square slab supported along four sides on a wooden frame. The slabs were supported on four sides on a wooden frame mounted on steel supports. A steel plate was placed on the slab to ensure that applied load is uniformly distributed over the slab surface. The slabs were loaded by manually operated hydraulic machine and readings taken as indicated by the dial gauge at failure of the slabs. Four of the slabs were designed to fail by rupture of reinforcement, which is tension failure. The other four slabs were designed to fail by crushing of concrete, which is compression failure.

\subsection{Design of Experimental Slabs}

Table 2 shows the details of test specimens, while the properties of the materials used in the experiment are shown in Table 3.

\subsection{Validation Procedure}

$S L A B$ 1: $(\mathrm{h}=150 \mathrm{~mm})$ for $8 \mathrm{~mm}$ diameter CFRP bar (Actual diameter $=7.98 \mathrm{~mm}$ )

Spacing of rods, $\mathrm{S}=150 \mathrm{~mm}$ centres

Concrete cover, $\mathrm{c}=2.5 d_{b}=2.5 \times 8=20 \mathrm{~mm}$

Effective depth, $d=150-\left(20+\frac{7.98}{2} \times 2\right)=122.02 \mathrm{~mm}$

Area of reinforcement, $A_{\text {frp }}=A_{b} \times \frac{1000}{S}$

$$
=333.427 \mathrm{~mm}^{2} / \mathrm{m}
$$

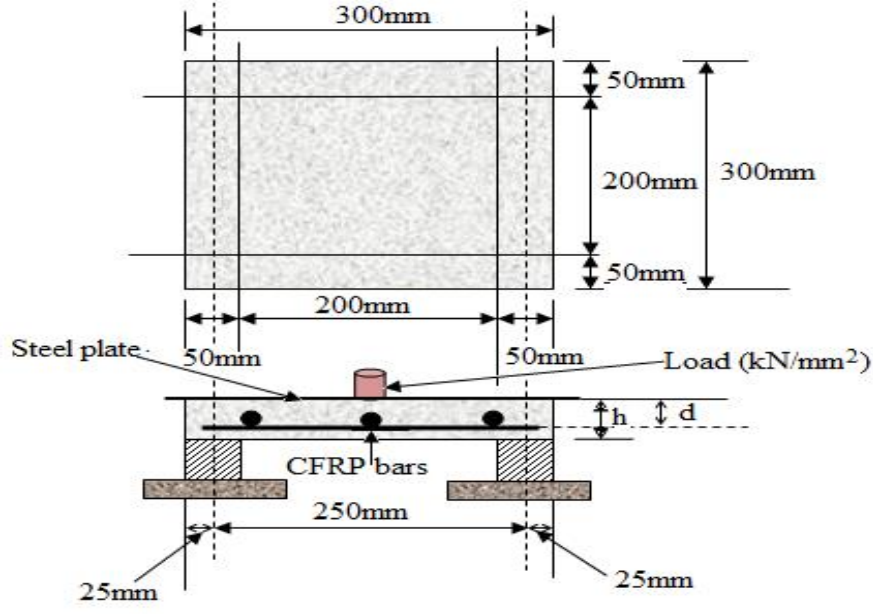

Figure 1: Schematic diagram of the test setup

Reinforcement ratio, $\rho_{\text {frp }}=\frac{A_{\text {frp }}}{b d}==0.00273$

Balanced reinforcement ratio, $\rho_{\text {frpb }}$

Balanced reinforcement ratio $\rho_{\text {frpb }}$

where,

$$
=\alpha_{1} \beta_{1} \frac{\phi_{c} f_{c}}{\phi_{f} f_{\text {frpu }}}\left(\frac{\varepsilon_{c u}}{\varepsilon_{c u}+\varepsilon_{\text {frpu }}}\right),
$$

$$
\begin{gathered}
\beta_{1}=0.97-0.0025 f_{c}^{\prime}=0.97-0.0025 \times 25=0.9075 \\
\geq 0.67,0 \mathrm{k} . \\
\alpha_{1}=0.85-0.0015 f_{c}^{\prime}=0.85-0.0015 \times 25=0.8125 \\
\geq 0.67,0 \mathrm{k},
\end{gathered}
$$

$\phi_{c}=0.6=$ material resistance reduction factor for concrete [6]

$\phi_{f}=0.75=$ material resistance factor for CFRP [6] 


$$
\begin{aligned}
& \rho_{\text {frpb }} \\
& =0.8125 \times 0.9075\left(\frac{0.60}{0.75}\right)\left(\frac{25}{1970}\right)\left(\frac{0.0035}{0.0035+0.013}\right) \\
& =0.00159<0.00273
\end{aligned}
$$

$\rho_{\text {frp }}>\rho_{\text {frpb }}$; Therefore failure will be by concrete crushing (Compression failure).

Stress in CFRP at ultimate limit state (ULS)

$$
\begin{aligned}
f_{f r p}=0.5 E_{f r p} \varepsilon_{c u} & {\left[\left[1+\frac{4 \alpha_{1} \beta_{1} f_{c}^{\prime}}{\rho_{f r p} \phi_{f r p} E_{f r p} E_{c u}}\right]^{1 / 2}-1\right] } \\
= & 1936 / \mathrm{mm}^{2}
\end{aligned}
$$

Moment of Resistance

$$
M_{r}=\phi_{f r p} f_{f r p} A_{f r p}\left(d-\frac{a}{2}\right)
$$

Neutral axis

$$
\begin{gathered}
a=\frac{\phi_{f r p} E_{f r p} \varepsilon_{f r p} A_{f r p}}{\phi_{c}\left(\alpha_{1} f_{c}^{\prime}\right) b}=40.42 \mathrm{~mm} \\
M_{\text {rcode }}=\phi_{\text {frp }} f_{\text {frp }} A_{f r p}\left(d-\frac{a}{2}\right)=49.29 \mathrm{kNm} / \mathrm{m} \\
M_{\text {crack }}=0.25 f_{r} b d^{2}=11.167 \mathrm{kNm} / \mathrm{m} \\
M_{\text {crackropt }}=0.3325 f_{r} b d^{2}=14.852 \mathrm{kNm} / \mathrm{m} \\
M_{\text {rexp }}=\alpha_{\text {sx }} n l_{x}^{2}=57.00 \mathrm{kNm} / \mathrm{m}
\end{gathered}
$$

where, $M_{\text {rcode }}$ is the moment of resistance given by the code, $M_{\text {crack }}$ is the cracking moment of concrete, $M_{\text {crackropt }}$ is the optimized cracking moment of concrete and $M_{\text {rexp }}$ is the moment of resistance due to experiment.

$S L A B$ 2: $(\mathrm{h}=100 \mathrm{~mm})$ for $8 \mathrm{~mm}$ diameter CFRP bar (Actual diameter $=7.98 \mathrm{~mm}$ )
Spacing of rods, $\mathrm{S}=150 \mathrm{~mm}$ centres

Concrete cover, $\mathrm{c}=20 \mathrm{~mm}$

Effective depth $d=100-20-\frac{7.98}{2} \times 2=72.02 \mathrm{~mm}$

Area of reinforcement, $A_{\text {frp }}=A_{b} \times \frac{1000}{S}=333.427 \mathrm{~mm}^{2} / \mathrm{m}$

$$
\text { Reinforcement ratio, } \rho_{f r p}=\frac{A_{f r p}}{b d}=0.00463
$$

Balanced reinforcement ratio, $\rho_{\text {frpb }}$

\begin{tabular}{|c|c|c|c|c|c|c|}
\hline $\begin{array}{l}\text { Slab } \\
\text { Thickness } \\
\text { (h) }\end{array}$ & $\begin{array}{l}\text { Bar } \\
\text { Diameter }\end{array}$ & $\begin{array}{l}\text { Slab } \\
\text { mark }\end{array}$ & $\begin{array}{c}\text { Area of } \\
\text { bar } \\
\left(\mathrm{mm}^{2}\right)\end{array}$ & $\rho_{f r p}$ & $\rho_{f r p b}$ & Predicted mode of failure \\
\hline $150 \mathrm{~mm}$ & $7.98 \mathrm{~mm}$ & SH150-D8 & 333.427 & 0.00273 & 0.00159 & $\begin{array}{l}\text { Compression failure } \\
\text { Crushing of concrete }\end{array}$ \\
\hline $150 \mathrm{~mm}$ & $7.98 \mathrm{~mm}$ & SH150-D8 & 333.427 & 0.00273 & 0.00159 & $\begin{array}{l}\text { Crushing of concrete } \\
\text { Tension failure }\end{array}$ \\
\hline $150 \mathrm{~mm}$ & $2.87 \mathrm{~mm}$ & SH150-D3 & 43.133 & 0.00034 & 0.00215 & Rupture of rebars \\
\hline $150 \mathrm{~mm}$ & $2.87 \mathrm{~mm}$ & SH150-D3 & 43.133 & 0.00034 & 0.00215 & $\begin{array}{l}\text { Rupture of rebars } \\
\text { Compression failure }\end{array}$ \\
\hline $100 \mathrm{~mm}$ & $7.98 \mathrm{~mm}$ & SH100-D8 & 333.427 & 0.00463 & 0.00159 & Crushing of concrete \\
\hline $100 \mathrm{~mm}$ & $7.98 \mathrm{~mm}$ & SH100-D8 & 333.472 & 0.00463 & 0.00159 & $\begin{array}{l}\text { Crushing of concrete } \\
\text { Tension failure }\end{array}$ \\
\hline $100 \mathrm{~mm}$ & $2.87 \mathrm{~mm}$ & SH100-D3 & 43.133 & 0.00056 & 0.00213 & Rupture of rebars \\
\hline $100 \mathrm{~mm}$ & $2.87 \mathrm{~mm}$ & SH100-D3 & 43.133 & 0.00056 & 0.00213 & Rupture of rebars \\
\hline
\end{tabular}

Balanced reinforcement ratio, $\rho_{\text {frpb }}$

$$
=\alpha_{1} \beta_{1} \frac{\phi_{c} f_{c}^{\prime}}{\phi_{f} f_{\text {frpu }}}\left(\frac{\varepsilon_{c u}}{\varepsilon_{c u}+\varepsilon_{f r p u}}\right) \text {, }
$$

$\rho_{\text {frpb }}=0.00159<0.00465 ; \rho_{\text {frp }}>\rho_{\text {frpb }}$;

$\rho_{\text {frp }}>\rho_{\text {frpb }}$; Therefore failure will be by concrete crushing (Compression failure).

Stress in CFRP at ultimate limit state (ULS)

$$
\begin{aligned}
f_{\text {frp }}=0.5 E_{f r p} \varepsilon_{c u} & {\left[\left[1+\frac{4 \alpha_{1} \beta_{1} f_{c}^{\prime}}{\rho_{\text {frp }} \phi_{\text {frp }} E_{\text {frp }} E_{c u}}\right]^{1 / 2}-1\right] } \\
= & 1434 \mathrm{~N} / \mathrm{mm}^{2}
\end{aligned}
$$

Moment of Resistance: $M_{r}=\phi_{f r p} f_{f r p} A_{f r p}\left(d-\frac{a}{2}\right)$

Neutral axis

$$
\begin{gathered}
a=\frac{\phi_{f r p} E_{f r p} \varepsilon_{f r p} A_{f r p}}{\phi_{c}\left(\alpha_{1} f_{c}^{\prime}\right) b}=40.42 \mathrm{~mm} \\
M_{\text {rcode }}=\phi_{\text {frp }} f_{\text {frp }} A_{f r p}\left(d-\frac{a}{2}\right)=18.58 \mathrm{kNm} / \mathrm{m} \\
M_{\text {crack }}=0.25 f_{r} b d^{2}=3.890 \mathrm{kNm} / \mathrm{m} \\
M_{\text {crackropt }}=0.3325 f_{r} b d^{2}=5.174 \mathrm{kNm} / \mathrm{m} \\
M_{\text {rexp }}=\alpha_{s x} n l_{x}^{2}=34.20 \mathrm{kNm} / \mathrm{m}
\end{gathered}
$$

Table 2: Details of test specimens

Table 3: Properties of Materials Used

\begin{tabular}{cccccc}
\hline $\begin{array}{c}\text { Diameter of } \\
\text { CFRP bar } \\
(\mathrm{mm})\end{array}$ & $\begin{array}{c}\text { Area of } \\
\text { CFRP bar } \\
\left(\mathrm{mm}^{2}\right)\end{array}$ & $\begin{array}{c}\text { Tensile strength } \\
\text { of CFRP bar } \\
\left(\mathrm{N} / \mathrm{mm}^{2}\right)\end{array}$ & $\begin{array}{c}\text { Ultimate of } \\
\text { CFRP bar } \\
\text { strain }\end{array}$ & $\begin{array}{c}\text { Elastic modulus } \\
\text { CFRP of bar } \\
\left(\mathrm{N} / \mathrm{mm}^{2}\right)\end{array}$ & $\begin{array}{c}\text { Compressive strength } \\
\text { of concrete }\left(\mathrm{N} / \mathrm{mm}^{2}\right)\end{array}$ \\
\hline $8(7.98)$ & 50.014 & 1970 & 0.0130 & 151538 & 25 \\
$3(2.87)$ & 6.47 & 1431 & 0.0119 & 120000 & 25 \\
\hline
\end{tabular}


SLAB 3: $(\mathrm{h}=150 \mathrm{~mm})$ for $3 \mathrm{~mm}$ diameter CFRP bar (Actual diameter $=2.87 \mathrm{~mm}$ )

Spacing of rods, $S=150 \mathrm{~mm}$ centres

Concrete cover, $\mathrm{c}=20 \mathrm{~mm}$

$$
\text { Effective depth } \begin{aligned}
d & =150-20-\left(\frac{2.87}{2} \times 2\right) \\
& =127.13 \mathrm{~mm}
\end{aligned}
$$

Area of reinforcement, $A_{\text {frp }}=A_{b} \times \frac{1000}{S}$

$$
=43.133 \mathrm{~mm}^{2} / \mathrm{m}
$$

Reinforcement ratio, $\rho_{\text {frp }}=\frac{A_{\text {frp }}}{b d}=0.000339$

Balanced reinforcement ratio, $\rho_{f r p b}$

Balanced reinforcement ratio, $\rho_{\text {frpb }}$

$$
\begin{aligned}
=\alpha_{1} \beta_{1} \frac{\phi_{c} f_{c}^{\prime}}{\phi_{f} f_{\text {frpu }}}\left(\frac{\varepsilon_{c u}}{\varepsilon_{c u}+\varepsilon_{\text {frpu }}}\right) \\
\rho_{\text {frpb }}=0.00234>0.000339
\end{aligned}
$$

$\rho_{\text {frp }}>\rho_{\text {frpb }}$; Therefore failure will be by CFRP rupture (Tension failure).

Stress in CFRP at ultimate limit state (ULS)

$$
\begin{aligned}
f_{\text {frp }}=0.5 E_{f r p} \varepsilon_{c u} & {\left[\left[1+\frac{4 \alpha_{1} \beta_{1} f_{c}^{\prime}}{\rho_{\text {frp }} \phi_{\text {frp }} E_{\text {frp }} E_{c u}}\right]^{1 / 2}-1\right] } \\
= & 5312 \mathrm{~N} / \mathrm{mm}^{2}
\end{aligned}
$$

Neutral axis

$$
\begin{gathered}
f_{\text {frp }}=\frac{f_{\text {frp }}}{E_{\text {frp }}}=0.0443 \\
c=\frac{\varepsilon_{c u}}{\varepsilon_{c u}+\varepsilon_{f r p}} \times d=9.309 \mathrm{~mm} \\
M_{\text {rcode }}=A_{\text {frp }} \phi_{\text {frp }} f_{\text {frp }}\left(d-\frac{\beta_{c}}{2}\right)=21.120 \mathrm{kNm} / \mathrm{m} \\
M_{\text {crack }}=0.25 f_{r} b d^{2}=12.122 \mathrm{kNm} / \mathrm{m} \\
M_{\text {crackropt }}=0.3325 f_{r} b d^{2}=16.122 \mathrm{kNm} / \mathrm{m} \\
M_{\text {rexp }}=\alpha_{\text {sx }} n l_{x}^{2}=53.20 \mathrm{kNm} / \mathrm{m}
\end{gathered}
$$

SLAB 4: $(\mathrm{h}=100 \mathrm{~mm})$ for $3 \mathrm{~mm}$ diameter CFRP bar (Actual diameter $=2.87 \mathrm{~mm}$ )

Spacing of rods, $\mathrm{S}=150 \mathrm{~mm}$ centres

Concrete cover, $\mathrm{c}=20 \mathrm{~mm}$

Effective depth, $d=100-20-\left(\frac{2.87}{2} \times 2\right)=77.13 \mathrm{~mm}$
Area of reinforcement, $A_{\text {frp }}=A_{b} \times \frac{1000}{S}=43.133 \mathrm{~mm}^{2} / \mathrm{m}$

Reinforcement ratio, $\rho_{f r p}=\frac{A_{f r p}}{b d}=\frac{43.133}{1000 \times 77.13}$

$$
=0.000559
$$

Balanced reinforcement ratio, $\rho_{\text {frpb }}$

Balanced reinforcement ratio, $\rho_{\text {frpb }}$

$$
\begin{array}{r}
=\alpha_{1} \beta_{1} \frac{\phi_{c} f_{c}^{\prime}}{\phi_{f} f_{\text {frpu }}}\left(\frac{\varepsilon_{c u}}{\varepsilon_{c u}+\varepsilon_{f r p u}}\right) \\
\rho_{\text {frpb }} 0.00234>0.000559
\end{array}
$$

$\rho_{\text {frp }}>\rho_{\text {frpb }}$; Therefore failure will be by CFRP rupture (Tension failure).

Stress in CFRP at ultimate limit state (ULS)

$$
\begin{aligned}
f_{f r p}=0.5 E_{f r p} \varepsilon_{c u} & {\left[\left[1+\frac{4 \alpha_{1} \beta_{1} f_{c}^{\prime}}{\rho_{f r p} \phi_{f r p} E_{f r p} E_{c u}}\right]^{1 / 2}-1\right] } \\
= & \frac{4092.403 N}{m m^{2}}
\end{aligned}
$$

Neutral axis

$$
\begin{gathered}
f_{\text {frp }}=\frac{f_{\text {frp }}}{E_{\text {frp }}}=0.0341 \\
c=\frac{\varepsilon_{c u}}{\varepsilon_{c u}+\varepsilon_{f r p}} \times d=7.18 \mathrm{~mm} \\
M_{\text {rcode }}=A_{\text {frp }} \phi_{\text {frp }} f_{\text {frp }}\left(d-\frac{\beta_{c}}{2}\right)=9.78 \mathrm{kNm} / \mathrm{m} \\
M_{\text {crack }}=0.25 f_{r} b d^{2}=4.462 \mathrm{kNm} / \mathrm{m} \\
M_{\text {crackropt }}=0.3325 f_{r} b d^{2}=5.934 \mathrm{kNm} / \mathrm{m} \\
M_{\text {rexp }}=\alpha_{\text {sx }} n l_{x}^{2}=34.2 \mathrm{kNm} / \mathrm{m}
\end{gathered}
$$

\section{RESULTS AND DISCUSSION}

The results of the failure modes are shown in Table 3. From the Table, it is evident that four of the slabs failed by crushing of concrete while the reinforcement remained elastic, and four failed by rupture of the reinforcement before concrete crushed. All the slabs failed as predicted.

The details of the failure moment of the tested CFRP reinforced concrete slabs are presented in Table 4. It is clear from the results that the resistance moment is affected by the depth of the section, aside reinforcement ratio, which determines failure mode.

Table 4: Failure Moments of Specimens

\begin{tabular}{cccccc}
\hline $\begin{array}{c}\text { Slab } \\
\text { Specimen }\end{array}$ & $\begin{array}{c}\mathrm{M}_{\text {rcode }} \\
(\mathrm{kNm} / \mathrm{m})\end{array}$ & $\begin{array}{c}\mathrm{M}_{\text {rcrack }} \\
(\mathrm{kNm} / \mathrm{m})\end{array}$ & $\begin{array}{c}\mathrm{M}_{\text {rcrackopt }} \\
(\mathrm{kNm} / \mathrm{m})\end{array}$ & $\begin{array}{c}\mathrm{M}_{\text {experiment }} \\
(\mathrm{kNm} / \mathrm{m})\end{array}$ & Failure Mode \\
\hline SH150-D8 & 49.29 & 11.167 & 14.852 & 57.000 & Compression failure (Crushing) \\
SH150-D8 & 49.29 & 11.167 & 14.852 & 57.000 & Compression failure (Crushing) \\
SH150-D3 & 21.12 & 12.122 & 16.122 & 53.200 & Tension failure (Rupture) \\
SH150-D3 & 21.12 & 12.122 & 16.122 & 53.200 & Tension failure (Rupture) \\
SH100-D8 & 18.58 & 3.890 & 5.174 & 34.200 & Compression failure (Crushing) \\
SH100-D8 & 18.58 & 3.890 & 5.174 & 34.200 & Compression failure (Crushing) \\
SH100-D3 & 9.78 & 4.462 & 5.934 & 34.200 & Tension failure (Rupture) \\
SH100-D3 & 9.78 & 4.462 & 5.934 & 34.200 & Tension failure (Rupture) \\
\hline
\end{tabular}


This is seen in the difference between the $\mathrm{M}_{\mathrm{r} \text {,code }}$ and $\mathrm{M}_{\mathrm{r} \text {,exp }}$ in the tension failure modes. This is expected since the reinforcement ruptures before the concrete crushes, proving that concrete has not reached its ultimate strain. It is interesting to note that the ratios of $\mathrm{M}_{\mathrm{r} \text {,crackopt }}$ to $\mathrm{M}_{\mathrm{r} \text {,code }}$ in the compression failure modes are 0.3013 for $150 \mathrm{~mm}$ thick slab, and 0.2785 for $100 \mathrm{~mm}$ thick slab, respectively; whereas the ratios of $\mathrm{M}_{\mathrm{r} \text {,crack }}$ to $\mathrm{M}_{\mathrm{r} \text {,code }}$ for the same slabs are 0.2266 and 0.2094 respectively. Taking the average of the two values, 0.3013 and 0.2785 , we have 0.2899 , which is approximately 0.29 . It is seen also that the ratio of $\mathrm{M}_{\mathrm{r}, \text { crackpot }}$ to $\mathrm{M}_{\mathrm{r} \text {,crack }}$ is 1.33 in both slabs of thickness $150 \mathrm{~mm}$ and $100 \mathrm{~mm}$. This means that the value of resistance moment of the concrete could be raised by about $33 \%$. This value agrees with the value earlier obtained by [7]. Thus, the moment of resistance of a singly CFRP reinforced rectangular solid slab section may be expressed as:

$$
M_{r}=0.3325 f_{r} b d^{2}
$$

\section{CONCLUSION}

This work has critically looked at the varying complexities connected with the structural behaviour of CFRP singly-reinforced concrete slab sections, generally in their design formulations. As in the design of steelreinforced concrete elements, the design requirements for FRP-reinforced concrete elements are strength requirements at the ultimate limit state and serviceability requirements for cracking and deflection. While the design of steel-reinforced elements is normally governed by the strength or ultimate limit state, FRPreinforced concrete members are controlled by serviceability requirements, such as crack widths and deflections.

The design formulations for predicting the minimum flexural resistance of an FRP-reinforced concrete member provided by [6], has been optimized deterministically. The design formulations were found to underestimate the resistance moment capacity of FRPreinforced concrete slabs by about $33 \%$ when considering the wholly rectangular stress block. This is the percentage underestimation of the cracking moment of concrete and validated in the laboratory by experiment. The findings herein lead to the following suggested equation to evaluate the resistance moment of FRP-reinforced rectangular concrete slabs:

$$
M_{u}=0.3325 f_{r} b d^{2}
$$

\section{REFERENCES}

[1] Micelli, F. and Nanni, A., "Mechanical Properties and Durability of FRP Rods", Centre for Infrastructure Engineering Studies, University of Missouri-Rolla, 2001.

[2] Micelli, F. and Nanni, A. "Durability of FRP rods for concrete structures" Construction and Building Materials, ELSEVIER, April, pp 491 -503. 2004.

[3] ISIS "Reinforcing Concrete Structures with Fibre Reinforced Polymers", Canada Research Network, September, 2007.

[4] Renée, C. and Yunping, X., "The Behavior of FiberReinforced Polymer Reinforcement in Low Temperature Environmental Climates", Report No. CDOT-DTD-R-2003-4, Colorado Department of Transportation Research Branch, December, 2002.

[5] ISIS, "An Introduction to FRP-Reinforced Concrete", Canada,www.isiscanada.com,2011.

[6] CSA-S806-02(R07), "Design and Construction of Building Components with Fibre- Reinforced Polymers", Canadian Standards Association, Toronto, 2007.

[7] Abejide, 0. S. and Okoro, E. E., "Material Cost Optimization of Resistance Moment of Solid Concrete Slabs Singly-Reinforced with CFRP", Proceeding of International Conference on Emerging Trends in Engineering and Technology, Association of Computer Electronics and Electrical Engineers, pp 878-883. DOI: 03AETS 2013.3.6, 2013,

[8] CSA S6-06 "Canadian Highway Bridge Design Code", 2006.

[9] Okoro, E. E., "Optimum Moment of Resistance of Concrete Slabs Reinforced With Carbon FibreReinforced Plastic (CFRP)", Unpublished PhD Thesis submitted to Postgraduate School, Ahmadu Bello University, Zaria, Nigeria, 2016. 